\title{
SUBJECT IT-EXTRAPOSITION IN APPLIED LINGUISTICS RESEARCH ARTICLES: SEMANTIC AND SYNTACTIC ANALYSIS
}

\author{
Reza Moghaddam \\ Seyed Foad Ebrahimi
}

\begin{abstract}
During the last two decades, numerous studies have focused on linguistic features of academic writing. One of these features, which appears frequently in academic writing and which writers need to improve their use of, is the it-extraposition construction. The existing literature on subject it-extraposition has focused on syntactic analysis (types and patterns) of this construction and little attention has been paid to semantic analysis (meanings); thus, this study aims to explore the types, patterns and meanings of subject it-extraposition used in Applied Linguistics research articles. The study was run on a corpus of 57 Applied Linguistics research articles, wherein the common extraposed subject clauses were the that-clause followed by the infinitive to-clause. It was also evident that minimal attention was devoted to the use of the wh-clause and the -ing participle clause. Concerning patterns of it-extraposition subject clause, subject + predicate and subject + predicate + complement were the most commonly utilised in Applied Linguistics research articles. The findings showed that Applied Linguistics writers were more concerned with expressing and evaluating their opinions and claims semantically. This study could help novice writers, especially novice non-native writers, to increase their awareness regarding how such construction is used syntactically and semantically by expert writers in writing research articles.
\end{abstract}

\section{Keywords}

subject it-extraposition, extraposed clause, research article, applied linguistics

\section{Introduction}

In recent decades, studies on written academic texts have increased. Researchers have examined academic texts for rhetorical organisations. Although they have focused on a range of texts from textbooks (Hyland 2010, Oldstone-Moore 2002) to conference papers (Rowley-Jolivet 2002), most of the attention has been devoted to the analysis of the research article (RA) as an important written academic genre. RAs and their sections have thus received attention from researchers. Concerning rhetorical organisations, the RA (Dressen-Hammouda 2014, Kanoksilapatham 2015, Lim 2012, Tessuto 2015), the introduction section (Fakhri 2004, Gledhill 2000, Ozturk 2007, Loi 
\& Evans 2010, Martín \& Pérez 2014, Samraj 2002), the method section (Bruce 2008, Swales 1990, Lim 2006, Gollin-Kies 2014), and the results and discussion section (Brett 1994, Holmes 1997, Hopkins \& Dudley-Evans 1988, Williams 1999, Ruiying \& Allison 2003, Peacock 2002, Bitchener \& Basturkmen 2006, Basturkmen 2012) have been investigated.

Some of these studies have concentrated on specific linguistic features of academic writing, for example the use of tense and aspect (Hinkel 2004), grammatical subject (Gosden 1993, Ebrahimi \& Chan 2015), modality (Vassileva 2001), stance nouns (Hyland \& Jiang 2016), self-mention (Harwood 2005), functions of adjectives (Soler 2002), nouns (Flowerdew 2003, Aktas \& Cortes 2008), and citations (Samraj 2013).

The studies reviewed here indicate that one of the linguistic features that has received little attention is "subject it-extraposition". Hewings and Hewings (2002) compared the functions of anticipatory it-clauses and the extraposed subject $i t$ in two corpora of journal articles from the field of Business Studies and MBA student dissertations written by non-native English speakers. They found that it-clause serves four functions: hedging, marking writers' attitudes, emphasis and attribution. The main difference between the two corpora was a significant variation in the use of the it-clause to persuade readers about the validity of claims. This study introduces a full description of extraposition in Section 2.

Furthermore, Zhang (2015) studied forms and meanings of subject it-extraposition in academic and popular writings. To this end, he compared academic and popular writings as sub-corpora within the informational writing category of ICE-GB (the British component of the International Corpus of English). The results demonstrated clear differences regarding subject it-extraposition in form and meanings: main clauses were passive in academic writing and the most common extraposed clause was the that-clause. Semantically, academic writing includes more clauses to explain and negotiate at the cost of evaluation.

Having these research efforts onboard, the motivation of this study is to highlight the types, patterns and meanings of subject it-extraposition in Applied Linguistics (AL) RAs. Thus, the intention is to answer the following questions:

1) How frequent are subject it-extraposition clauses in AL RAs and their sections (introduction, method, results and discussion)?

2) What types of subject it-extraposition clauses are used in AL RAs and their sections?

3) What are the patterns of subject it-extraposition clauses in AL RAs and their sections?

4) What are the semantic meanings conveyed by predicates of subject it-extraposition clauses in AL RAs and their sections? 


\section{Methodology}

\subsection{Corpus}

This study was carried out on a corpus of 57 RAs from two journals: English for Specific Purposes and Journal of English for Academic Purposes. These two journals are high impact leading journals in AL. The online versions of both titles are available at ScienceDirect.com, the world's leading platform for high quality peer-reviewed full-text journals. The corpus was extracted from issues published in the five years from 2011 to 2015. It consisted of 385,846 words (from 57 articles), with the introduction sections being represented by 110,927 words, the method sections represented by 81,000 words, and the results and discussion sections represented by 193,919 words. The RAs were written using Swales' (1990) model of RAs: Introduction-Method-Results-Discussion (IMRD). Articles containing these four sections (IMRD) were included in the research and those which did not follow this construction were excluded. The results and discussion sections were considered as one section due to the fact that these sections were merged as one section in the majority of the RAs in the corpus. The corpus of this study belongs to the AL discipline because the researchers are English as second language (ESL) instructors who teach academic writing, which includes teaching RA writing.

\subsection{The framework}

This study aimed to analyse the form and function of subject it-extraposition. To this end, the data requires a framework for syntactic and semantic classifications. These are discussed below, but prior to that the definition and structure of subject it-extraposition are reviewed.

\subsubsection{Subject it-extraposition}

Extraposition is a movement of the element of the sentence from its normal position to the end of sentence as in the following example:

(1) To retrieve a comprehensive list of reporting verbs is quite impossible.

(2) It is quite impossible to retrieve a comprehensive list of reporting verbs.

In Example 1, a long main clause is used in the subject position. In Example 2 , with the help of it-extraposition movement, the writer has moved the long main clause to the predicate position and filled the subject position with the it-extraposition clause. According to Quirk et al. (1985) extraposition is 
a device of postponement that serves the two principles of "end-focus" and "end weight". Moreover, Richards and Schmidt (2013) stated that the "heavy" structures are placed at the end of the sentence because dominant clauses are better "encoded" and "decoded" at the end of the sentence (Celce-Murcia \& Larsen-Freeman 1983). Moreover, Bloor and Bloor (1995) observed that the longer and the more complicated the clause, the more likely it is to be extraposed. For example:

(3) Whether NS and NNS writers use bundles for different functions is unclear.

(4) It is unclear whether NS and NNS writers use bundles for different functions.

In the first sentence the weight or information of the sentence lies in the first part, whereas in the second sentence the subject is postponed until the end of the sentence. This construction is more likely to occur in formal and academic writing and a failure to pay attention to it will lead to understanding difficulties (Zhang 2015).

\subsubsection{Syntactic classification}

One area of considerable focus has been syntactic analysis of extraposed sentences (e.g. Huddleston \& Pullum 2002, Kaltenböck 2005, Quirk et al. 1985). Collins (1994), among all, conducted a complete investigation regarding the syntactic analysis of infinitive clauses examined by Mair (1990) and other extraposed elements. This framework includes four types of clause patterns:

1) "Subject + Predicator + Complement" (SPC)

2) "Subject + Predicator" (SP)

3) "Subject + Predicator + Object" (SPO)

4) "Subject + Predicator + Indirect Object + Direct Object"

\subsubsection{Semantic classification}

Besides syntactic analysis, there is a need for semantic analysis of extraposed sentences. Many studies have explored semantic classification with regards to the main clause of extraposed sentences (e.g. Biber et al. 1999, Charles 2000, Groom 2005, Kaltenböck 2004, Mindt 2011); however, these studies might not have dealt with the overall organisation of the main clause of extraposed sentences. Consequently, this study focused on the semantic classification of main verbs used in predicates of the extraposed clause. For this aim, Herriman's (2000) classification was used for active verbs while Biber et al.'s (1999) classification was used for passive verbs. Herriman's (2000: 585-586) classification of semantic active verbs is stated as follows: 
1) Epistemic modality including those predicates expressing "the speaker's opinion, existence, and claims concerning the content of the extraposed clause" (e.g. it is clear)

2) Deontic modality representing "obligation and volition" (e.g. it is desirable)

3) Dynamic modality typically involving a participant's "ability or power to carry out a course of action" (e.g. it is difficult)

4) Evaluation involving general evaluation, appropriateness, significance, frequency, emotive reaction, and responsibility (e.g. it is interesting)

The classification of semantic meaning of passive verbs given by Biber et al. (1999: 587):

1) Activity verbs which are concerned with what people do (e.g. use, give, measure)

2) Communication verbs involving communication activities such as speaking and writing (e.g. describe, discuss)

3) Mental verbs describing cognitive states and activities (e.g. know, believe), which also include attitudinal or emotional states (e.g. prefer, love, enchant)

4) Verbs of existence or relationship denoting that a relation or a state exists between entities (e.g. include, represent, define)

5) Verbs of facilitation or causation indicating a new state of affairs brought about (e.g. cause, allow)

6) Verbs of simple occurrence reporting the occurrence of events (e.g. develop, grow)

7) Aspectual verbs denoting the stage of progress of events or activities (e.g. keep, continue)

\subsection{Procedure}

The study went through the following procedures. First, the corpus was downloaded and saved from the English for Specific Purposes journal and the Journal of English for Academic Purposes. These RAs were considered as ones which have been written by successful writers as these RAs were extracted from publications which are among the leading, highest impact ELT journals. These journals publish RAs only after strict review (usually twice blind-review) by experts within the AL discipline. As these two journals are high-impact, RAs which get published in these journals are considered to be of a high standard. In this study, the aspect of being native or non-native writers of English was not considered. This is supported by Myers (1989). The RAs which followed Swales' model (IMRD) were included in the research and the RAs which did 
not follow this approach were excluded. Next, all the examples of extraposed it-subject in active and passive clauses were selected and collected from the corpus. Third, the types of extraposed sentences were indicated using Collins' (1994) classification and the pattern of extraposed sentences was identified using Herriman's (2000) classification. As Herriman's (2000) classification does not consider passive verbs, the semantic classification of Biber et al. (1999) was used for passive verbs. The final step is comparing the results of analysis of extraposed it-subject in each section of AL RAs and reporting a conclusion based on the analysis of the data.

\section{Findings and discussion}

\subsection{Frequency of subject it-extraposition}

As can be seen in Table 1, the frequency of subject it-extraposition is 1.32 per 1,000 words. This result is more than that reported by Hewings and Hewings (2002) ( 0.95 per 1,000 words), which could be attributed to the corpus analysed in both studies. In this study AL RAs were examined, whereas Hewings and Hewings (2002) explored Management RAs. Thus, it could be concluded that disciplinary background knowledge (AL in this study) can have an influence on writers in terms of using subject it-extraposition.

The results in Table 1 also indicate that among the RA sections, the writers showed the greatest attention to this structure in the introduction section; conversely, the method section received the least attention. One possible justification for this result might be the rhetorical function of these two sections.

\begin{tabular}{|l|r|r|r|}
\hline RAs sections & \multicolumn{1}{|l|}{ Word count } & Frequency & Per 1,000 words \\
\hline Introduction & 106,927 & 169 & 1.58 \\
\hline Method & 79,600 & 82 & 1.03 \\
\hline Results and discussion & 187,919 & 249 & 1.32 \\
\hline Total & 374,446 & 500 & 1.32 \\
\hline
\end{tabular}

Table 1: Frequency of subject it-extraposition

\subsection{Types of extraposed clauses}

The results in Table 2 indicate that, in the analysed RAs, the most common type of it-extraposed subject clause is the that-clause (58\%) (Example 5) followed by to-infinitive clauses (34\%) (Example 6). This finding is in line with 
the evidence reported by Zhang (2015), who analysed academic writing and reported the predominance of the that-clause $(50 \%)$; thus, it can be said that using this type of clause is common in academic writing.

(5) It is crucial that the researcher read the preceding and following sections to understand how the information is related.

(6) It was possible to see the stages in the creation of the texts and to trace each student's contribution.

The results also showed that other types of clauses have received minimal attention. The results concerning types of subject it-extraposition clauses are presented in Table 2.

\begin{tabular}{|l|c|c|c|c|c|c|}
\hline Type of Clause & that- & to- & wh- & zero & -ing & Frequency \\
\hline Frequency & 292 & 172 & 26 & 6 & 4 & 500 \\
\hline Percentage & $58 \%$ & $34 \%$ & $25 \%$ & $2 \%$ & $1 \%$ & $100 \%$ \\
\hline
\end{tabular}

Table 2: Frequency and percentage of subject it-extraposition clause types in AL RAs

The results in Table 3 demonstrate that in all sections of AL RAs, the that-clause was most commonly used followed by the to-infinitive clause. This possibly indicates that writers of AL RAs prefer to use clause types that leave them with more choices of extraposition in predicates.

A closer look at the figures in Table 3 indicates that writers of AL RAs prefer to employ the that-clause in the results and discussion section. This could suggest that such a clause enables writers to present their findings in an explicit way. Such extrapositioning helps in hedging the findings and leaves the responsibility for research to others, thus freeing the researchers (Example 7).

(7) It may be a coincidence that these five engineering subjects, which happen to involve life- or biology-related content, seem to be more difficult to read.

The results regarding types of subject it-extraposition clauses in sections of AL RAs are presented in Table 3. 
Reza Moghaddam, Seyed Foad Ebrahimi

\begin{tabular}{|l|c|c|c|c|c|c|}
\hline & that- & to- & wh- & zero & -ing & Total \\
\hline Introduction & $94(56 \%)$ & $56(33 \%)$ & $17(10 \%)$ & $2(1 \%)$ & - & $169(100 \%)$ \\
\hline Method & $44(54 \%)$ & $34(42 \%)$ & $2(2 \%)$ & $1(1 \%)$ & $1(1 \%)$ & $82(100 \%)$ \\
\hline $\begin{array}{l}\text { Results } \\
\text { and discussion }\end{array}$ & $154(62 \%)$ & $82(33 \%)$ & $7(3 \%)$ & $3(1 \%)$ & $3(1 \%)$ & $249(100 \%)$ \\
\hline RA & $292(58 \%)$ & $172(34 \%)$ & $26(5 \%)$ & $6(2 \%)$ & $4(1 \%)$ & $500(100 \%)$ \\
\hline
\end{tabular}

Table 3: Frequency and percentage of subject it-extraposition clause types in sections of AL RAs

\subsection{The main clause patterns of subject it-extraposition sentences}

The results in Table 4 indicate that the most frequent clause pattern of extraposed sentence is SPC (62\%), as shown in Example 8. As demonstrated in Example 9, the other pattern which received noticeable attention is SP (37\%). The last pattern, which is SPO, is rarely used in AL RAs (1\%). This result is in line with Zhang (2015) and could suggest that the use of this pattern is not normal in AL RAs or possibly in the corpus of this study.

(8) It is important to understand whether the quality of student writing is judged on these features or whether other may be more relevant.

(9) It should be pointed out that in Iran, as a norm, many subject teachers with reasonable English proficiency are invited to teach EAP courses.

The results also highlight that among the different AL RA sections, writers made significant use of the SPC pattern in the introduction and method sections (57\%); however, the greatest attention was devoted to the results and discussion section $(67 \%)$.

\begin{tabular}{|l|r|r|r|r|}
\hline RAs sections & \multicolumn{1}{|c|}{ SP } & \multicolumn{1}{c|}{ SPC } & \multicolumn{1}{c|}{ SPO } & \multicolumn{1}{|c|}{ Total } \\
\hline Introduction & $73(43 \%)$ & $96(57 \%)$ & - & 169 \\
\hline Method & $35(43 \%)$ & $47(57 \%)$ & - & 249 \\
\hline Results and discussion & $79(32 \%)$ & $168(67 \%)$ & $2(1 \%)$ & 500 \\
\hline RAs & $187(37 \%)$ & $311(62 \%)$ & $2(1 \%)$ & 240 \\
\hline
\end{tabular}

Table 4: Frequency and percentage of the main clause patterns of subject it-extraposition sentences 


\subsection{Semantic meanings of passive verbs in extraposed sentences}

The results in Table 5 indicate that passive verbs were used to present four semantic meanings. They are mental, communication, existence or relationship, and facilitation and causation verbs. Mental passive verbs occurred most frequently in the RAs and passive verbs of facilitation and causation received the least attention (Examples 10-13). One possible justification for these findings might be that, by nature, AL RAs impose the use of mental passive verbs.

(10) It was found that the writers continued presenting the results and justifying them in extended paragraphs without providing citation to support.

(11) It is now recognized that there are significant differences between acquiring an $L 1$ and learning an $L 2$.

(12) ..., it is believed that it can be used in describing the rhetorical functions of citations in academic writing from other disciplines that are also empirically based.

(13) It was revealed that novice writers used these citations considerably less compared to expert writers as these citations need more awareness of the complex rhetorical functions and advanced disciplinary knowledge. 


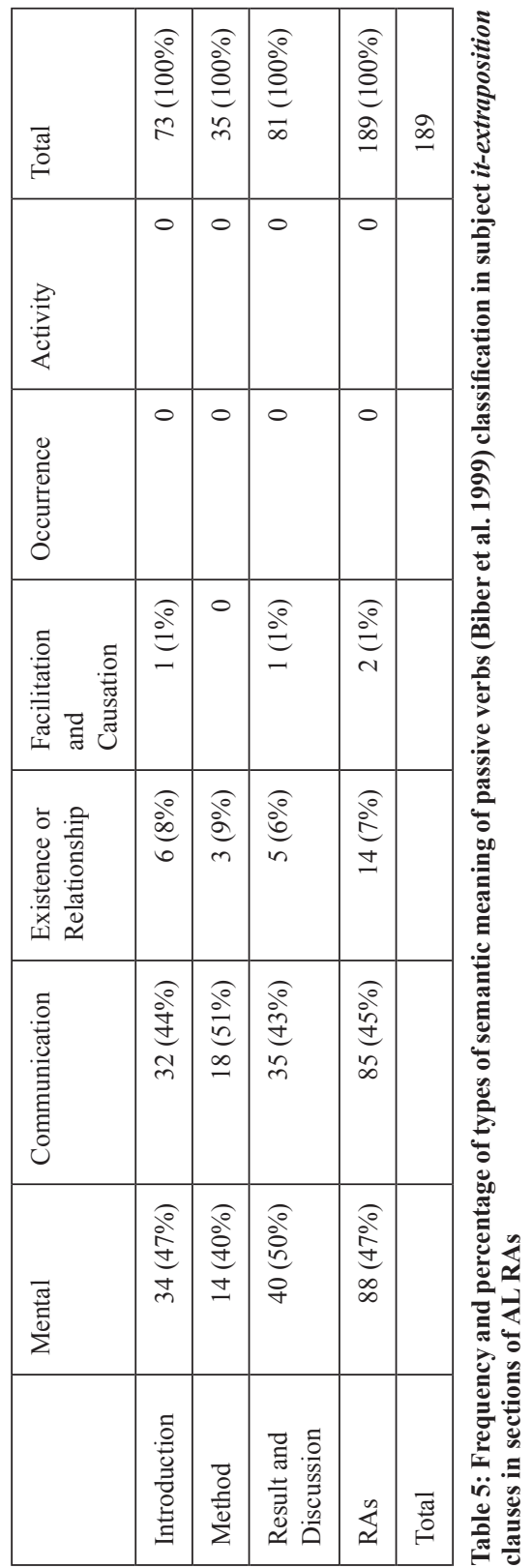


Next in the frequency list is communication passive verbs (45\%) (Example 14). The use of this kind of passive verb is unsurprising as RAs constitute a communicative genre wherein writers try to communicate the important aspects of their study, for example the gap in literature (Example 15), features of the corpus (Example 16), and their justification of the results (Example 17) to community members.

(14) Accordingly, it was suggested that writing teaching practice may help the students avoid transferring the L1 thinking of ideas and organization into their L2 essay writing.

(15) It should be noted that in postgraduate education at the Master's and doctoral levels the institutions awarding the degree usually prepare assessment criteria.

(16) It should be pointed out that one research article has a separate conclusion section following the discussion section while two research articles have a sub-section labeled conclusion or concluding remarks within the discussion section.

(17) Again, it can be noted that as the size of the cluster increases, the similarity between the most frequent clusters in both corpora decreases.

In addition, it was conveyed that verbs with existence or relationship meaning received noticeable attention (Example 18). This could potentially be because in AL RAs, writers are reporting a study they have conducted themselves.

It appeared that the result will be generalized to all groups.

\subsection{Semantic meanings of active verbs in extraposed sentences}

The data analysed with regards to the semantic meaning of predicates of extraposed clauses and results are presented in Table 6 . These findings provide evidence that evaluative modality has received the greatest attention while the other three semantic categories were comparatively unpopular. Evaluative modality was used to state appropriateness, significance, emotive reaction, frequency and general evaluation (Examples 19-23). The findings presented here are partially in line with Zhang (2015). Such statements are usual in discourses such as RAs which must be valid, significant and receive sufficient support to get published and read.

(19) It is therefore somewhat understandable that Hiro chose to focus part of his response on Britain. 
(20) It is therefore worth examining how these different subdisciplines construct knowledge through RAs (i.e., how knowledge is formulated, transformed, and acknowledged as new).

(21) It is thus of interest to investigate whether the RAs of different sub-disciplines are organizationally identical.

..., it is common for collaborative groups to consist of both NSE and NNSE students.

(23) It may be useful to first discuss our criteria in terms of what was not included.

Epistemic modality was the other extensively used semantic category in three rhetorical sections $(33 \%)$. The use of epistemic modality suggests that writers insisted on the truth of the content of rhetorical sections within RAs (Example 24). Moreover, this modality was employed more regularly in the introduction and results and discussion sections. This could be due to the fact that, in these two rhetorical sections, writers are presenting their research and highlighting their findings and thus need to clearly state that the content is true and valid.

(24) It is clear that attributive adjectives, the resource on which they draw more heavily than all other modifiers put together, are a favoured structure for the EAP students.

The less frequent usage of the other two semantic categories could be justified as such semantic meanings are not favoured by RA writers.

\begin{tabular}{|l|r|r|r|r|r|}
\hline & $\begin{array}{l}\text { Epistemic } \\
\text { Modality }\end{array}$ & $\begin{array}{l}\text { Deontic } \\
\text { Modality }\end{array}$ & $\begin{array}{l}\text { Dynamic } \\
\text { Modality }\end{array}$ & \multicolumn{1}{l|}{$\begin{array}{l}\text { Evaluative } \\
\text { Modality }\end{array}$} & \multicolumn{1}{l|}{ Total } \\
\hline Introduction & $37(39 \%)$ & $4(4 \%)$ & $6(6 \%)$ & $49(51 \%)$ & $96(100 \%)$ \\
\hline Method & $11(23 \%)$ & $5(11 \%)$ & $7(15 \%)$ & $24(51 \%)$ & $47(100 \%)$ \\
\hline Result and Discussion & $54(32 \%)$ & $7(4 \%)$ & $19(11 \%)$ & $88(53 \%)$ & $168(100 \%)$ \\
\hline RAs & $102(33 \%)$ & $16(5 \%)$ & $32(10 \%)$ & $161(52 \%)$ & $311(100 \%)$ \\
\hline
\end{tabular}

Table 6: Semantic meaning of active verbs (Herriman 2000) 


\section{Conclusion}

The aim of this study was to analyse the form and function of subject it-extraposition in AL RAs. The findings indicated that the introduction section contains the greatest concentration of this structure while the method section contains the least amount. One possible justification for this result might be the rhetorical function of these two sections. In the introduction section, writers have to emphasise the centrality of topic, criticise existing literature, and highlight the significance of the study. To meet these functions, writers prefer to deflect attention from themselves and shift the focus to extraposed claims. Moreover, writers have to be more objective and responsible for their data selection, procedure and analysis and as a consequence less frequent use of such structure compared to other RA sections could be expected.

The findings also showed that the common extraposed subject clauses were the that-clause followed by the infinitive to-clause, with little attention paid to the use of the wh-clause and the -ing participle clause. This could be due to the fact that this type of clause can perform different meanings compared to other types of clauses that result in different predicates with different extraposed elements. Lower use of the to-infinitive clause compared to the that-clause was also demonstrated in the study conducted by Zhang (2015), which potentially indicates that it is a norm in academic writing to prioritise the that-clause as opposed to the to-infinitive clause. The other possible justification is that the toinfinitive clause is more fixed than the that-clause. For example, in the introduction section all to-infinitive clauses were SPC. Thus, the writers of AL RAs prefer to use types of clauses that leave them with more choices of extraposition in predicates. The minimal usage of other clause types might indicate that there is no room for clauses such as ing-clauses in the list of preferences of writers as such clauses serve a limited number of functions. This could also suggest that using such clauses is not a norm in academic writing genres such as RAs and writers may prefer other clause types.

Concerning the pattern of the it-subject extraposed subject clause, two patterns of SP and SPC are commonly used in AL RAs. The SPC clause has received the greatest attention in AL RAs, which is in line with evidence reported by Zhang (2015) and Collins (1994). The next pattern which is commonly used in AL RAs is the SP clause. Although the results concerning this pattern are also in line with the findings of Zhang (2015), there is a higher percentage than that reported by Collins (1994). The difference could be attributed to the data analysed in these studies. Collins (1994), for instance, analysed a corpus including spoken and written data, while only written data was investigated in this study. Thus, it seems that this type of clause is used more regularly in written data compared 
to spoken data. The other patterns are rarely used in AL RAs. There appears to be no room for such patterns in academic writing or possibly researchers prefer another structure to serve such functions.

The findings in relation to passive verbs suggested that, in line with Zhang (2015), mental passive verbs have received the greatest attention in the three sections of RAs, while passive verbs of facilitation and causation have received the least attention. One possible justification for this might be the nature of RAs as they impose the use of mental passive verbs; these verbs help the writer to signify his/her presence and involvement in the research. Mental passive verbs were used in all three sections of the RAs as the predominant semantic meaning, which is a consequence of the fact that mental passive verbs enable writers to justify the study in the introduction section, clarify the procedure steps in the method section, and state the findings in the results and discussion section. Next in the frequency list was communication passive verbs. The use of this kind of verb is not surprising as RAs are a communicative genre wherein writers attempt to communicate the important aspects of their study, for instance the gap in literature, features of the corpus, and the justification of the results to community members.

The next finding indicates that evaluative modality has been most widely employed while other three semantic categories have received little attention. Evaluative modality was used to state appropriateness, significance, emotive reaction, frequency and general evaluation, and such statements are usual in discourses such as RAs which must be valid, significant and receive sufficient support to get published and read. Epistemic modality was the other semantic category that received noticeable attention from writers in all three rhetorical sections. Epistemic modality is used by writers to emphasise the truth of the content of rhetorical sections within RAs. This result indicates that this modality was used more frequently in the introduction and results and discussion sections. In these two rhetorical sections, writers are presenting their research and highlighting their findings; thus, it is necessary to clearly state that the content is true and valid.

\section{Implications}

Teachers and RAs writers should become conscious of the different sections of RAs in teaching and writing this structure. Based on their needs, they can use the structure semantically and syntactically in different sections; for instance, it can be utilised in the introduction section to highlight research gaps, in the method section to emphasise the methodology, and in the results and discussion section to distance themselves from their findings. 


\section{Limitations}

This study was undertaken to investigate the form and function of subject it-extraposition in different AL RA sections. To achieve this goal, the following limitations were made. First, this study did not address disciplinary variations concerning the use of subject it-extraposition. Thus, the RAs were related to the same discipline. Second, more research needs to be done on subject it-extraposition with passive matrix predicates, which has mostly been excluded in previous studies on extraposition. Third, since the study was based on a fairly small corpus, more research on different sections of RAs is necessary in the future.

\section{Suggestions for further studies}

The results of this study, which aimed to analyse the form and function of subject it-extraposition in different sections of AL RAs, can illuminate a number of areas for further research. First, it is also possible to investigate the pattern of subject it-extraposition in different sections of different genres. Second, the number of articles can be increased to obtain better results via a large number of extraposed sentences. Finally, the pattern of subject it-extraposition can be compared in different sections of an MA (Master of Art) thesis.

\section{References}

Aktas, R. N. and Cortes, V. (2008) 'Shell nouns as cohesive devices in published and ESL student writing.' Journal of English for Academic Purposes 7(1), 3-14.

Basturkmen, H. (2012) 'A genre-based investigation of discussion sections of research articles in dentistry and disciplinary variation.' Journal of English for Academic Purposes 11(2), 134-144.

Bitchener, J. and Basturkmen, H. (2006) 'Perceptions of the difficulties of postgraduate L2 thesis students writing the discussion section.' Journal of English for Academic Purposes 5(1), 4-18.

Biber, D., Johansson, S., Leech, G., Conrad, S., Finegan, E. and Quirk, R. (1999) Longman Grammar of Spoken and Written English. London: Longman.

Bloor, T. and Bloor, M. (1995) The Functional Analysis of English. A Hallidayan Approach. London: Arnold.

Brett, P. (1994) 'A genre analysis of the results section of sociology articles.' English for Specific Purposes 13(1), 47-59.

Bruce, I. (2008) 'Cognitive genre structures in Methods sections of research articles: A corpus study.' Journal of English for Academic Purposes 7(1), 38-54.

Celce-Murcia, M. and Larsen-Freeman, D. (1983) The Grammar Book: An ESL/EFL Teacher's Course. Rowley, MA: Newbury House.

Charles, M. (2000) 'The role of an introductory it pattern in constructing an appropriate academic persona.' In: Thompson, P. (ed.) Patterns and Perspectives: Insights into EAP Writing Practice. Reading: The University of Reading. 45-59.

Collins, P. (1994) 'Extraposition in English.' Functions of Language 1(1), 7-24. 
Dressen-Hammouda, D. (2014) 'Measuring the voice of disciplinarity in scientific writing: A longitudinal exploration of experienced writers in geology.' English for Specific Purposes 34, 14-25.

Ebrahimi, S. F. and Chan, S. H. (2015) 'Research article abstracts in Applied Linguistics and Economics: Functional analysis of the grammatical subject.' Australian Journal of Linguistics 35(4), 381-397.

Fakhri, A. (2004) 'Rhetorical properties of Arabic research article introductions.' Journal of Pragmatics 36(6), 1119-1138.

Flowerdew, J. (2003) 'Signalling nouns in discourse.' English for Specific Purposes 22(4), 329-346.

Gledhill, C. (2000) 'The discourse function of collocation in research article introductions.' English for Specific Purposes 19(2), 115-135.

Gollin-Kies, S. (2014) 'Methods reported in ESP research articles: A comparative survey of two leading journals.' English for Specific Purposes 36, 27-34.

Gosden, H. (1993) 'Discourse functions of subject in scientific research articles.' Applied Linguistics 14(1), 56-75.

Groom, N. (2005) 'Pattern and meaning across genres and disciplines: An exploratory study.' Journal of English for Academic Purposes 4(3), 257-277.

Harwood, N. (2005) "Nowhere has anyone attempted... In this article I aim to do just that": A corpus-based study of self-promotional $I$ and we in academic writing across four disciplines.' Journal of Pragmatics 37(8), 1207-1231.

Herriman, J. (2000) 'Extraposition in English: A study of the interaction between the matrix predicate and the type of extraposed clause.' English Studies 81(6), 582-599.

Hewings, M. and Hewings, A. (2002) "II is interesting to note that...": A comparative study of anticipatory 'it' in student and published writing.' English for Specific Purposes 21(4), 367-383.

Hinkel, E. (2004) 'Tense, aspect and the passive voice in L1 and L2 academic texts.' Language Teaching Research 8(1), 5-29.

Holmes, R. (1997) 'Genre analysis, and the social sciences: An investigation of the structure of research article discussion sections in three disciplines.' English for Specific Purposes 16(4), 321-337.

Hopkins, A. and Dudley-Evans, T. (1988) 'A genre-based investigation of the discussion sections in articles and dissertations.' English for Specific Purposes 7(2), 113-121.

Huddleston, R. and Pullum, G. K. (2002) The Cambridge Grammar of the English Language. Cambridge: Cambridge University Press.

Hyland, K. (2010) 'Hedges, boosters and lexical invisibility: Noticing modifiers in academic texts.' Language Awareness 9(4), 179-197.

Hyland, K. and Jiang, F. (2016) 'Change of attitude? A diachronic study of stance.' Written Communication 33(3), 251-274.

Kaltenböck, G. (2005) 'It-extraposition in English: A functional view.' International Journal of Corpus Linguistics 10(2), 119-159.

Kanoksilapatham, B. (2015) 'Distinguishing textual features characterizing structural variation in research articles across three engineering sub-discipline corpora.' English for Specific Purposes 37, 74-86.

Lim, J. M. H. (2006) 'Method sections of management research articles: A pedagogically motivated qualitative study.' English for Specific Purposes 25(3), 282-309.

Lim, J. M. H. (2012) 'How do writers establish research niches? A genre-based investigation into management researchers' rhetorical steps and linguistic mechanisms.' Journal of English for Academic Purposes 11(3), 229-245. 
Loi, C. K. and Evans, M. S. (2010) 'Cultural differences in the organization of research article introductions from the field of educational psychology: English and Chinese.' Journal of Pragmatics 42(10), 2814-2825.

Mair, C. (1990) Infinitival Complement Clauses in English: A Study of Syntax in Discourse. Cambridge: Cambridge University Press.

Martín, P. and Pérez, I. K. L. (2014) 'Convincing peers of the value of one's research: A genre analysis of rhetorical promotion in academic texts.' English for Specific Purposes 34, 1-13.

Mindt, I. (2011) Adjective Complementation: An Empirical Analysis of Adjectives Followed by That-Clauses. Amsterdam and Philadelphia: John Benjamins.

Myers, G. (1989) 'The pragmatics of politeness in scientific articles.' Applied Linguistics 10(1), 1-35.

Oldstone-Moore, J. (2002) Confucianism: Origins, Beliefs, Practices, Holy Texts, Sacred Places. Oxford: Oxford University Press.

Ozturk, I. (2007) 'The textual organisation of research article introductions in Applied Linguistics: Variability within a single discipline.' English for Specific Purposes 26(1), 25-38.

Peacock, M. (2002) 'Communicative moves in the discussion section of research articles.' System 30(4), 479-497.

Quirk, R., Greenbaum, S., Leech, G. and Svartvik, J. (1985) A Comprehensive Grammar of the English Language. London: Longman.

Richards, J. C. and Schmidt, R. W. (2013) Longman Dictionary of Language Teaching and Applied Linguistics. London: Routledge.

Rowley-Jolivet, E. (2002) 'Visual discourse in scientific conference papers: A genrebased study.' English for Specific Purposes 21(1), 19-40.

Ruiying, Y. and Allison, D. (2003) 'Research articles in applied linguistics: Moving from results to conclusions.' English for Specific Purposes 22(4), 365-385.

Samraj, B. (2002) 'Introductions in research articles: Variations across disciplines.' English for Specific Purposes 21(1), 1-17.

Samraj, B. (2013) 'Form and function of citations in discussion sections of master's theses and research articles.' Journal of English for Academic Purposes 12(4), 299-310.

Soler, V. (2002) 'Analysing adjectives in scientific discourse: An exploratory study with educational applications for Spanish speakers at advanced university level.' English for Specific Purposes 21(2), 145-165.

Swales, J. (1990) Genre Analysis: English in Academic and Research Settings. Cambridge: Cambridge University Press.

Tessuto, G. (2015) 'Generic structure and rhetorical moves in English-language empirical law research articles: Sites of interdisciplinary and interdiscursive cross-over.' English for Specific Purposes 37, 13-26.

Vassileva, I. (2001) 'Commitment and detachment in English and Bulgarian academic writing.' English for Specific Purposes 20(1), 83-102.

Williams, I. A. (1999) 'Results sections of medical research articles: Analysis of rhetorical categories for pedagogical purposes.' English for Specific Purposes 18(4), 347-366.

Zhang, G. (2015) 'It is suggested that... or it is better to...? Forms and meanings of subject it-extraposition in academic and popular writing.' Journal of English for Academic Purposes 20, 1-13. 
Reza Moghaddam has M.A. in ELT from Islamic Azad University, Abadan Branch. He is interested in discourse analysis studies, especially studies on systemic functional analysis. His main areas of research are text analysis and discourse studies. He has published two papers and participated in three international conferences.

Address: Reza Moghaddam, M.A., Department of English, Abadan Branch, Islamic Azad University, Abadan, Iran. [e-mail: rmoghaddam65@yahoo.com]

Seyed Foad Ebrahimi is Assistant Professor at Islamic Azad University, Shadegan Branch. He is interested in discourse analysis studies, especially studies on systemic functional analysis. His main areas of research are text analysis and discourse studies. He has published more than 40 papers and participated in more than 20 international conferences.

Address: Seyed Foad Ebrahimi, Ph.D., Department of English, Shadegan Branch, Islamic Azad University, Shadegan, Iran. [e-mail: seyedfoade@gmail. com] 